\title{
Publisher's Note: Multicellular density fluctuations in epithelial monolayers [Phys. Rev. E 92, 032729 (2015)]
}

Steven M. Zehnder, Marina K. Wiatt, Juan M. Uruena, Alison C. Dunn, W. Gregory Sawyer, and Thomas E. Angelini (Received 26 July 2016; published 3 August 2016)

DOI: 10.1103/PhysRevE.94.029901

This paper was published online on 30 September 2015 with an incorrect figure. Figure 1 has been replaced as of 22 July 2016. The figure is incorrect in the printed version of the journal; therefore, for the benefit of the print readership, the figure and its caption are replicated below.

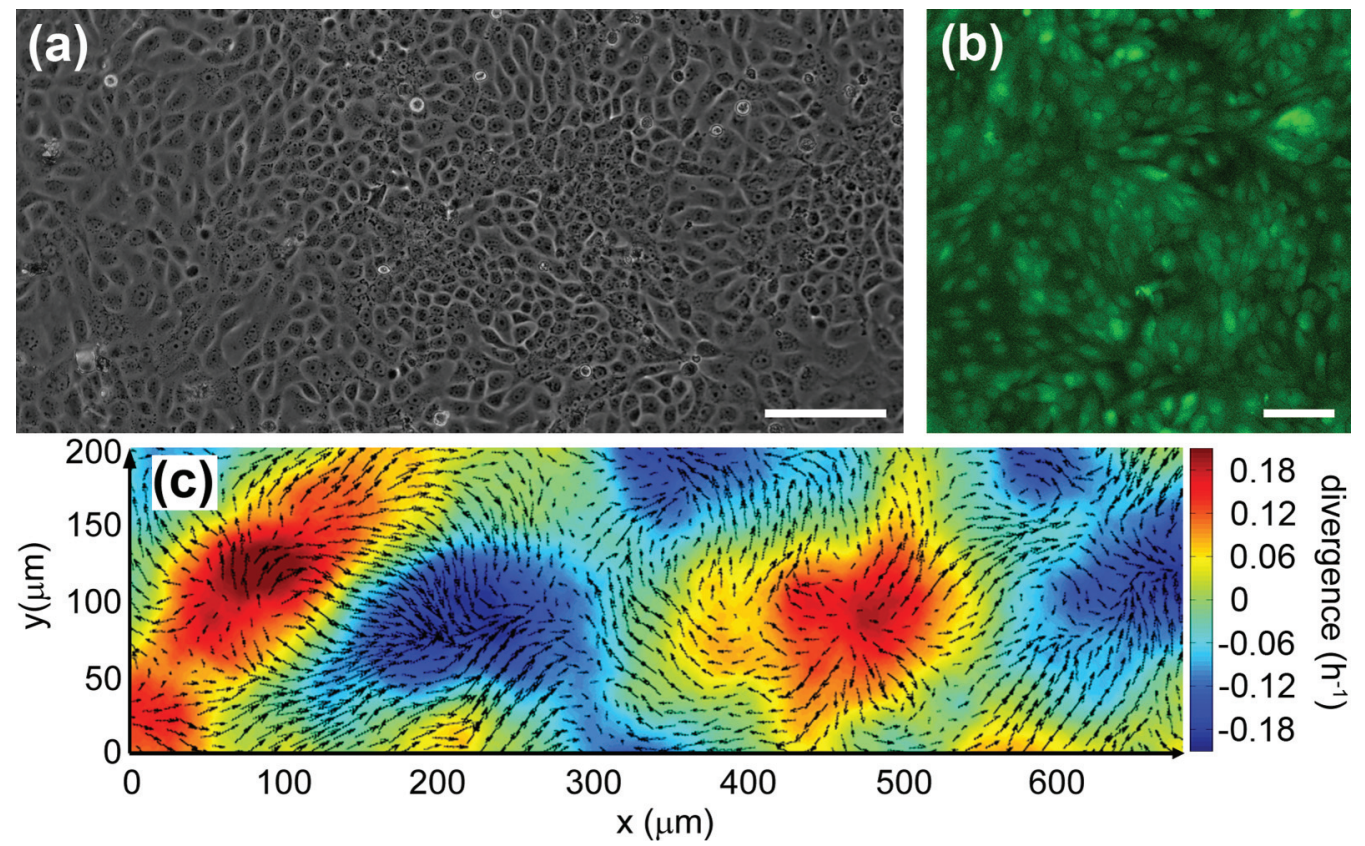

FIG. 1. (a) Phase contrast microscopy of a confluent MDCK monolayer exhibits a patchy, heterogeneous cell number density distribution; scale bar $=150 \mu \mathrm{m}$. (b) To study fluid flow between regions of cells, the layer is dyed with membrane-impermeable dye that concentrates and dilutes with changes in cell volume; scale bar $=100 \mu \mathrm{m}$. (c) Velocity fields of cell motion superimposed on top of divergence fields show coherent patterns of spreading (positive) and contracting (negative) regions spanning hundreds of microns. 